\title{
EXTENSIVE OR INTENSIVE GENEROSITY? THE PRICE AND INCOME EFFECTS OF FEDERAL GRANTS
}

\author{
Katherine Baicker \\ Working Paper 8384 \\ http://www.nber.org/papers/w8384 \\ NATIONAL BUREAU OF ECONOMIC RESEARCH \\ 1050 Massachusetts Avenue \\ Cambridge, MA 02138 \\ July 2001
}

I thank David Cutler, Howard Chernick, Martin Feldstein, Claudia Goldin, Lawrence Katz, Jonathan Skinner, and especially Douglas Staiger for innumerable helpful comments. I am grateful to the National Institute on Aging and the National Science Foundation for support. The views expressed herein are those of the author and not necessarily those of the National Bureau of Economic Research.

(C) 2001 by Katherine Baicker. All rights reserved. Short sections of text, not to exceed two paragraphs, may be quoted without explicit permission provided that full credit, including (C) notice, is given to the source. 
Extensive or Intensive Generosity?

The Price and Income Effects of Federal Grants

Katherine Baicker

NBER Working Paper No. 8384

July 2001

JEL No. H5, H7

\begin{abstract}
When TANF replaced AFDC in 1996 the marginal subsidy for state welfare spending was eliminated. This paper exploits data from a period in the history of AFDC when the structure of federal subsidies and legislative changes allow us to estimate not only the price and income elasticities of federal grants, but also to disentangle state reactions to subsidies along two different dimensions: the intensive margin of spending per recipient, and the extensive margin of spending on additional recipients. I find that states respond much more strongly to these incentives than previous analyses that neither adequately controlled for the endogeneity of prices nor estimated the two margins separately would imply. I show that state spending on benefits per recipient responds significantly to the marginal price of benefits, with an elasticity of -.38 , and that state spending on the number of recipients responds significantly to the marginal price of additional recipients, with an elasticity of -.34. Cross-price elasticities are positive, implying a substitutability of extensive for intensive generosity and indicating that an analysis that groups the two margins together masks significant behavioral responses along each dimension. These results correspond very well to estimates of the early effects of TANF, predicting a significantly larger drop in caseloads than in benefits.
\end{abstract}

\author{
Katherine Baicker \\ Department of Economics \\ Dartmouth College \\ 6106 Rockefeller Hall \\ Hanover, NH 03755-3514 \\ and NBER \\ Katherine.Baicker@Dartmouth.edu
}




\section{INTRODUCTION}

1996 saw the enactment of sweeping welfare reform, with Temporary Assistance for Needy Families replacing Aid to Families with Dependent Children, which had been the primary federal safety net program since its inception in 1935. In addition to imposing work requirements and time limits, TANF replaced the federal match rate that had subsidized state AFDC spending with a block grant, effectively increasing the marginal price of state welfare spending from the previous range of .18 to .5 to a new level of 1 . The effect of this leap in the marginal cost of state spending is an open question that has fueled much recent research, in part because previous estimates of the price and income elasticities of state spending had ranged so widely as to make reasonably precise policy predictions difficult. This paper takes advantage of data from a period in the history of AFDC when the structure of federal subsidies and legislative changes allow us to estimate not only the price and income elasticities of federal grants using more plausibly exogenous variation, but also how states react to subsidies along two different margins: the intensive margin of spending per recipient, and the extensive margin of spending on additional recipients. States have the ability to choose both the extent of welfare eligibility and the intensity of benefits provided through the program, but for the last 35 years AFDC and now TANF have provided the same marginal federal subsidy for both kinds of spending. Previous estimates of state price elasticities using data from this recent period have necessarily collapsed state behavior along these two dimensions. The model and data used in this paper, however, provide separate precise estimates of the price elasticities of intensive and extensive welfare spending, allowing us to analyze a much wider range of potentially untapped policy instruments. 
There is a significant body of research estimating state price and income elasticities with respect to federal grants in general and to the AFDC program in particular, producing a wide range of estimates. Chernick (1998) and Ribar and Wilhelm (1999) review and try to reconcile some of these studies, but all suffer from a lack of clear empirical identification driven by their use of post-1965 AFDC data. After 1965, the state AFDC match rate was based on relative state income (using the same formula as Medicaid), and the formula determining the rate did not change over time, which made it difficult to disentangle the relationship between income, the match rate, and spending during this time period. Since the match rate (or "price" of AFDC) was an exact function of state relative income, it was not possible to identify these effects without making assumptions about functional form. Richer states systematically received lower federal contributions, and may also have systematically differed in their AFDC spending. For example, changes in the economic climate could drive both changes in per capita income (which determines the price of AFDC spending), and changes in the underlying poverty rate (which determines AFDC eligibility), and both of these may also change desired benefit levels. Controlling for income and economic variables would mitigate this problem, but only if the correct functional form were specified.

Prior to 1965 , however, there were significant legislative variations in the structure of the program. From 1935 to 1958, all states faced a federal match schedule based on their spending per recipient: the greater the recipient spending per month, the lower the federal contribution became at the margin. This step function was amended 6 times between 1946 and 1958. In 1958 legislation was introduced that made the match rate for some ranges of state spending depend on state per capita income relative to national per capita income. I use these changes to generate instruments for the actual marginal prices and income effects of the federal grant in order to 
produce estimates of price and income elasticities that are not biased by the endogenous relationship between income, spending, and federal contributions.

The usual match rate and income formulation masks another dimension of state responsiveness to federal policy. I show that there are two margins along which states may adjust their AFDC spending, and thus two relevant marginal prices. First, they can adjust the benefits per month that each recipient receives, or the intensive generosity. The marginal price of increasing this monthly benefit amount is the marginal state share determined by the step function described above. Second, they can adjust the number of recipients through eligibility requirements (and the strictness of enforcement of other criteria), or the extensive generosity. The marginal price of expanding eligibility is the average state share of current benefits. While states always have the choice of movement along both the intensive and extensive margins, after 1965 these two prices were the same, making disentanglement impossible. Furthermore, the average share could easily be confounded with the income effect of federal AFDC funds. Several previous studies interpret large income coefficients as evidence of a flypaper effect (where federal grants "stick" within the budget they are allocated to without the expected displacement of state funds) without analyzing adjustment along an alternate margin. One previous explanation for observed flypaper phenomena is the confusion of marginal and average costs when making decisions (see Hines and Thaler, 1995), but the two costs are indistinguishable in the post-1965 period.

Using state-year data from 1948 to 1963, I find that state benefits per recipient are very sensitive to the marginal cost of benefits (with an elasticity of around -.4) and the number of recipients per capita is sensitive to the marginal cost of recipients (with an elasticity around -.3), and that cross-price elasticities are positive. The elasticity of total state spending is just the 
product of these two margins, and when they are combined the observed effect of the price of benefits is much smaller and the effect of the price of recipients is near zero. Observations of the combined effect along the two margins masks significant responses to prices in opposite directions.

These separate price effects on benefits and recipients have strong implications for the efficiency of different financial structures for welfare grants. With two policy instruments at its disposal, the federal government can affect the mix of spending being done at the state level. If there are different externalities (either within or between states) associated with increasingly extensive eligibility or increasingly intensive benefit levels, the extent to which these activities are subsidized across states ought to be different. Given state concern about interstate mobility of welfare recipients based on program generosity and given the interconnectedness of eligibility for federal and state programs such as AFDC and Medicaid, such externalities are likely to be important and variable.

I begin with a review of previous estimates of the price and income elasticities of state AFDC spending and outline a theoretical framework for the analysis, and then give a brief history of AFDC legislation and the jurisdictional issues raised by the joint nature of the program. I describe the data used for this study, and present new estimates of the elasticities of state spending, as well as the responsiveness of the generosity of benefits, eligibility standards, and program features. I conclude with a discussion of the results.

\section{Theory And Previous Estimates}

Previous estimates of the responsiveness of state spending on AFDC to the level and matching rate of federal contributions have been subject to biases generated by the nature of the 
matching grant. Before 1965, by statute, states received a lower matching rate as their spending per recipient increased, with a cap on total federal reimbursement per recipient. The introduction of matching rates based on state per capita income in 1958 further complicated the endogenous relationship between a state's resources and its reimbursement rate, as states with lower per capita income were eligible for higher matching funds. Regressing spending on the match rate without accounting for this endogenous relationship could thus yield biased estimates of the sensitivity of state spending to the federal match rate. In addition, after 1965 the "price" of AFDC spending was also the price of Medicaid spending for most states, and eligibility across programs was often linked, further complicating estimation of elasticities.

A simple model of a state maximization function helps to clarify the relationship among previous studies and outlines a framework for this estimation. Suppose that the state objective (perhaps but not necessarily generated by a median voter) is to choose $B$, the benefit amount per recipient, and $R$, the number of recipients, to maximize

$$
U_{i}=u\left(c_{i}, B_{i}, R_{i} ; X_{i}\right)
$$

where $c$ is individual consumption, subject to the budget constraint

$$
y_{i}=c_{i}+\frac{R_{i}}{N_{i}} P\left(B_{i}, y_{i}\right) B_{i}
$$

where $N$ is the number of taxpayers in the state, y is per capita income, and $P(B, y)$ is the fraction of benefits paid by the state (with the remainder subsidized by the federal government). This model is more general than that of some previous analyses in that it allows the states to choose not only the benefit amount but also the number of recipients, and it allows the federal match rate to vary with the benefit amount and state income. States did indeed have a fair amount of

\footnotetext{
${ }^{1}$ I follow Ribar and Wilhelm's notation to the extent possible.
} 
freedom to determine eligibility standards throughout the program's history, and even more so during the early period, as discussed below. This being the case, the number of recipients should appear in the utility function as well as in the budget constraint, given that if states did not value recipients positively at least over some range they could set eligibility standards so as to have none. The other generalization that I have added, a federal match rate that depends on benefit levels, is consistent with the law in this period. We could make the number of recipients a function of the benefit amount, as Chernick (1998) and many others do, but that would not change the estimating equation derived below.

This model does not directly incorporate the externalities that may be imposed by increasing $R$ or $B$. While any externalities imposed within a state (such as unpaid medical costs or crime associated with poverty or increased take-up rates associated with higher benefits) ought to be incorporated in the state's objective function, externalities imposed between jurisdictions (such as on other states or the federal government) might not be.

If we make no assumptions about the form of the utility function (such as additive separability of the number of recipients and the benefit amount), the first order condition is

$$
\frac{\frac{\partial u}{\partial R}}{\frac{\partial u}{\partial B}}=\frac{P(B, y) B}{R\left(P(B, y)+\frac{\partial P}{\partial B} B\right)}
$$

or the marginal rate of substitution of recipients for benefits is just equal to the marginal cost of adding one recipient (the numerator on the right) over the marginal cost of adding one dollar to the benefit amount (the denominator on the right). The optimal $B$ and $R$ will thus be functions of both the price function and its derivative, or 


$$
\begin{aligned}
& R_{i}^{*}=f\left(y_{i}, P\left(B_{i}, y_{i}\right), \frac{\partial P}{\partial B_{i}} ; Z_{i}\right) \\
& B_{i}^{*}=g\left(y_{i}, P\left(B_{i}, y_{i}\right), \frac{\partial P}{\partial B_{i}} ; Z_{i}\right)
\end{aligned}
$$

The cost of adding a recipient is the average state portion of benefits, while the cost of increasing the benefit amount is the marginal state portion of benefits for each recipient. The amount of money that a state receives from the federal government as part of this program, often included as a covariate with an estimated coefficient interpreted as the income effect, is a function of $P$, or $R B(1-P(B, y))$.

Chernick (1998) and Ribar and Wilhelm (1999) review and try to reconcile some of the numerous studies estimating the price and income effects of federal matching grants. In these studies "price" is defined as one minus the federal match rate, which does not depend on $R$ or $B$ in this period, but does depend on state income. Chernick's review presents estimates of the price elasticity of the federal match rate relying on different assumptions functional form or exogeneity assumptions that range from -.96 to .58 and estimates of the income elasticity that range from .15 to $2.3^{\text {口 }}$ He speculates that estimates may vary so widely because of sample selection and the confounding of state income and the federal match formula. Ribar and Wilhelm compile a data set that allows them to replicate several different specifications. They

\footnotetext{
${ }^{2}$ For example, Larry Orr (1976) estimates the price effect of the AFDC subsidy on benefit levels per recipient. He includes lagged recipients/population as an exogenous covariate, and does not allow states to change the number of recipients in response to changes in prices. He includes separate price and income effects, and finds only price significant, estimating a price-elasticity of benefit levels of -.23 , concluding that federal funds are almost completely offset by state reductions. However, with no exogenous variation in the state share, his two-stage procedure relies solely on non-linearities for identification, and does not disentangle the relationship between state income and the state share. Robert Moffitt (1984) estimates a price elasticity using non-linearities in the post-1965 budget constraint. He develops an econometric technique for estimating state location choice along a piecewise-linear budget constraint and, using data from 1970, finds a significant and positive income effect, a smaller price effect than Orr of -.15, and no flypaper effect (by letting the income effect of AFDC be different from the effect of other income). Again, there is no exogenous variation in the price, so the estimation relies on functional form and simulations for identification, and the endogeneity of prices may bias the estimates.
} 
examine the effect of price and income on AFDC generosity per recipient using data from 1969 to 1992 , and find a weak price effect, with estimates bounded between -.14 and .02 , and a small but significant income elasticity bounded between .11 and .82. They conclude that differences in methodology drove the disparities in previous results, and that once appropriate fixed effects are included endogeneity does not produce significant biases. However, they must assume that the variables they use to instrument for price (such as benefits in neighboring states and the female unemployment rate) are not otherwise related to AFDC benefit levels, and the measure of income that they use is just the state's per capita income, which may have very different effects from the federal welfare grant (because of flypaper effects, principal-agent problems between bureaucrats

and voters, etc.). Furthermore, the majority of the studies ${ }^{3}$ focus on the intensive margin, or the benefit per recipient, alone, ignoring possible effects of the extensive margin of AFDC spending, or the number of recipients. Thus, none of these studies has a convincing way to disentangle the relationships among price, income, and spending that are generated by the AFDC formula that has been in place since 1965 .

\section{BRIEF History OF AFDC}

\section{Funding and Benefits}

The program Aid to Dependent Children was created by the Social Security Act of 1935. Since the program's inception, states had considerable freedom to determine eligibility, need standards, and benefit amounts. It was jointly financed by the states and the federal government: the federal government contributed some fraction of every dollar spent by the states. Figure 1

\footnotetext{
${ }^{3}$ Craig (1994) and Craig and Inman (1986) are exceptions.
} 
shows the step functions used to generate the federal share. Figure 2 shows a sample budget constraint for a state with an endowment of $\$ 5000$ and 100 recipients (since federal subsidies in this period are per dollar per recipient, not per total dollars). Until 1958 the federal reimbursement rate to states was a step function based solely on the amount that the states paid to individual recipients. In 1935 the reimbursement schedule was $1 / 3$ of the first $\$ 18$ per month for the first child plus $1 / 3$ of the first $\$ 12$ per month for each additional dependent child. These rates were amended in 1939, 1946 (when additional steps were added), 1948, 1950 (when the eligibility of one needy relative was allowed), 1952, and 1956. Throughout this period, the basic structure of the matching schedule remained the same, and all states continued to face the same schedule.

In 1958 the schedule was amended to create a range of spending within which federal reimbursement rates were based on state per capita income relative to national per capita income, and all calculations became based on average payments. The federal match rate was 14/17 for the first $\$ 17$ per recipient, ranged from 50 percent to 65 percent for the next $\$ 13$ per recipient, and was 0 thereafter. The variable match rate for the middle segment was based on the formula

$$
\alpha_{A F D C}=0.5 *\left(\frac{\text { state per capita income }}{\text { national per capita income }}\right)^{2}
$$

The federal matching rate decreased as state income relative to national income increased, and was bounded between 50 percent and 65 percent, with matching rates for all states with aboveaverage per capita income capped at 50 percent. The state share was thus:

$$
\text { state share }_{A F D C}= \begin{cases}.18 & \text { for } B \leq 17 \\ \max \{0.35, \min [0.5, \alpha]\} & \text { for } 17<B \leq 30 \\ 1 & \text { for } 30<B\end{cases}
$$

\footnotetext{
${ }^{4}$ The summary of the legislative history of the AFDC program is drawn almost entirely from CRS Report 82-62
} 
In 1965 the Medicaid program was created, with its own income-based reimbursement schedule. The Medicaid formula was similar to the matching portion of the AFDC formula, but without the caps based on spending per recipient. The state share was, and continues to be, based on formula (6), but with the .5 replaced by .45 , and $\alpha$ bounded between .50 and .18 , and does not vary with the amount the state spends. Thus the marginal price and the average price are the same across the range of state spending. States with approved Medicaid programs were free to choose between the old AFDC schedule and the new Medicaid schedule to determine their AFDC share. Because of the nominal kinks in the AFDC matching schedule, and the failure of Congress to make any additional adjustments to those nominal rates, the Medicaid schedule soon became more generous than the AFDC formula for almost all states. By 1978 all but 4 states (Arizona, Mississippi, South Carolina, and Texas) used the Medicaid formula. ${ }^{\text {日 }}$

\section{Jurisdiction and Discretion}

At its inception, the Aid to Dependent Children program (authorized under Title IV of the Social Security Act) was grouped together with other non-contributory welfare programs, most of which operated largely under state and local control (Gordon, 1994). While ADC dollars were matched at the federal levels, states were not required to have such a program, and, if they chose to have one, were permitted to exert as much or as little control over the administration of the program as they saw fit, determining both eligibility and benefit amounts, and often allowing localities to evaluate applicants with a kind of discriminatory criteria not typically seen in federally-controlled contributory programs.

EPW (1982).

${ }^{5}$ Throughout this adjustment period several states failed to utilize the formula offering the higher return. See CRS (1982) for documentation and potential explanations. 
The effect of this freedom was often to allow localities to determine eligibility in such a way that white citizens were over-represented in the recipient pool. This discriminatory determination of eligibility carried over to benefit amount determination as well. Black women were expected to work in jobs that white women weren't, and were expected to live on less; even when state-wide standards dictated benefit amounts, localities used differential cost-of-living adjustments to manipulate benefit levels (Gordon, 1994). Bell (1965) notes that "suitable home" requirements (dictating that benefits could only be given when eligible children resided in a suitable home), seasonal employment policies, and illegitimacy exclusions all tended disproportionately to exclude non-whites in the south. ${ }^{6}$ I include an analysis of the effect of the federal subsidy rate on the use of "suitable home" and work requirements below.

\section{DATA}

I use data on AFDC spending, the federal match rate available to each state, and other economic and demographic covariates, all at the state-year level. All dollar amounts are in real 2000 dollars. Because the introduction of the Medicaid program along with the Medicaid matching formula in 1965 considerably changed the resources and mechanisms states had at their disposal, I limit my sample to the years 1948 to 1963 . This period encompasses 5 changes in the federal matching formula for AFDC.

Data on state AFDC expenditures and total spending, per capita income, the number of AFDC recipients, and births by race come from annual issues of the Statistical Abstract of the

\footnotetext{
${ }^{6}$ Bell (1965) documents the use of "suitable home" requirements to discriminate against potential non-white recipients. A public outcry followed Louisiana's use of such a provision to reduce its welfare rolls by 25 percent in 1960. (95 percent of the children removed were black, although they represented only 66 percent of the recipient pool.) It was this crisis that led to the Flemming Ruling in 1961, which was the first step in limiting the discriminatory use of suitable home provisions.
} 
United States. Data on the "covered" unemployment rate come from the Unemployment Insurance Handbook, and refer to spells of unemployment covered by unemployment insurance. Information on the AFDC matching formula comes from the Congressional Research Service publication Analysis of Federal-State Cost-Sharing in the Aid to Families with Dependent Children Program. This information is used both to impute the actual state share and to construct the simulated state share using legislative changes.

More detailed information on individual state program rules are available for the years 1952, 1955, 1957, and 1959 from the Department of Health, Education, and Welfare publication Characteristics of State Public Assistance Plans Under the Social Security Act. These volumes contain information about program characteristics such as work requirements and benefit caps.

As the summary statistics in Table 1 show, during this period AFDC spending accounted for about 3 percent of total state spending, and almost 25 percent of state public welfare spending. In these years, state shares mechanically increased as state spending increased. While the average state share of AFDC spending was only 39 percent, states paid 74 percent on the margin.

\section{Estimating Price and Income Elasticities}

This analysis offers two innovations: first, the use of data from a time period with exogenous price variation, and second, the use of those structural differences in the program to decompose state price elasticities along the intensive and extensive margins. In order to facilitate comparisons to previous literature and to provide a benchmark for the decomposition, I begin 
with estimates of the usual (aggregate) price elasticity, and introduce the simulated price and income instruments I will use in this context. These instruments are related to the actual prices and federal contribution and are driven by changes in the federal match rate schedule rather than state incomes and state spending. I then move on to estimate intensive and extensive spending elasticities using these instruments, and compare the results of the new model with the more traditional formulation, including analysis of the effect of prices and income on spending, benefit amounts, and recipiency rates.

\section{Aggregate Price and Income Elasticities}

In the post-1965 period, the price of spending a dollar by adding a recipient and the price of spending a dollar by increasing benefits per recipient were the same (both infra- and intermarginally): every dollar spent was subsidized at the state's federal match rate. In the period before 1965 this match rate applied only to additional benefits, and varied over the range of benefits, so it is not strictly comparable to that used by authors analyzing the later period. Nevertheless, it is the closest comparison "price" during this period, so I begin with an analysis of the effect of the marginal state share (or 1 minus the match rate) on spending.

A first estimate of the sensitivity of state AFDC spending to the match rate can be made by regressing state spending on the marginal state share of a one dollar transfer and the income states receive from the federal government through AFDC. I run the OLS regression

$$
\ln (\text { AFDCSpending })_{i t}=\beta_{i}+\delta_{t}+X_{i t} \gamma+\lambda \ln (\text { marginal state share })_{i t}+\theta \ln (\text { federal AFDC contribution })_{i t}+\varepsilon_{i t}
$$


where $X_{i t}$ includes the $\log$ of per capita personal income and the $\log$ of the covered unemployment rate. The marginal state price is the fraction of additional spending (on benefits in this period) that would have to be financed by the state. Since the number of recipients and the total amount of spending is known for each state in each year, I calculate the marginal state share using the concurrent federal legislation. The federal AFDC contribution is just the total real per capita dollar amount contributed through the federal match for AFDC spending. Table 2 presents results with and without this term to show the importance of its inclusion.

These OLS results suggest a positive elasticity of state spending to the price of AFDC transfers: the higher the state share, the more it will transfer. The results in column (1), which exclude an income effect from federal funds, show a price elasticity of AFDC spending of .42, implying that a 10 percent increase in the state share would increase state AFDC spending by 4.2 percent. This confounds the effect of the marginal cost of further state spending with the income effect of the total federal contribution. Column (2) includes both. While the price effect declines, it is still positive and statistically (and economically) significant. Including the income generated by the federal grant here allows us to interpret the elasticity implied by the coefficient on price as a Slutsky compensated price elasticity.

These price results seem implausible, and are in fact likely driven by the mechanical relationship between state spending and federal contributions during the sample time period. (In fact, throughout the existence of the program the prices faced by a state were related to its spending or its income.) Since federal contributions decrease as a step function of state spending, states that spend more on AFDC for any reason will automatically receive lower federal reimbursement at the margin. This mechanical relationship would generate a positive estimate of the state price elasticity even if there were no behavioral response to prices at all. In 
addition to this mechanical relationship, state incomes are negatively correlated with state prices after 1958. If richer states choose to transfer more through AFDC independently of the positive effect of income on prices, that would also bias up estimates of the price sensitivity of AFDC spending.

In order to abstract from these relationships, as well as any other omitted variables such as unobserved economic conditions, I construct "simulated" marginal prices and federal incomes, based on the legislative changes outlined above. I use state AFDC spending in 1948, the initial year of my sample, and concurrent federal legislation to project what each state's marginal and average share would be in each year if spending continued at the same real levels, assuming that real benefits per recipient and the number of recipients as a fraction of the population remain constant. (Simulations using alternate assumptions, such as that benefits grow at the same rate as other spending produce very similar results.) In other words, if states did not change real benefits or the recipiency rate, what marginal price would they face and what would the total federal contribution be under the current legislation in each year? The summary statistics presented in Table 1 show that the actual and simulated values are quite similar.

I use the simulated price and contribution as instruments for the actual values. These instruments rely on the variation in initial spending levels and on changes in the federal statutes, and unlike the actual marginal price and federal contribution are uninfluenced by the spending choices made by the states after the initial period. The first stages are thus:

$$
\begin{aligned}
& \ln (\text { actual share })_{i t}=\beta_{1 i}+\beta_{1 t}+X_{i t} \gamma_{1}+\delta_{1} \ln (\text { simulated share })_{i t}+\phi_{1} \ln (\text { simulated fed AFDC income })_{i t}+\varepsilon_{1 i t} \\
& \ln (\text { actual fed AFDC income })_{i t}=\beta_{2 i}+\beta_{2 t}+X_{i t} \gamma_{2}+\delta_{2} \ln (\text { simulated share })_{i t}+\phi_{2} \ln (\text { simulated fed AFDC income })_{i t}+\varepsilon_{2 i t}
\end{aligned}
$$


The advantage of using this simulated instruments is that neither the mechanical relationship between spending and federal matching funds nor omitted controls for economic conditions should bias the estimates of state responsiveness. The simulated variables isolate legislative conditions, and are not affected by local economic or political conditions, nor by actual state spending in any given year. The joint $\mathrm{F}$ statistic for the instruments in equation (9) is 13.33 (with a p-value of .0000) and in equation (10) is $13.56(.0000) .8$

Estimating state price and income elasticities using these instruments gives a very different picture of state behavior than the OLS regressions did: the price elasticity is negative, as we would expect, but is not significantly different from zero once the income effect of federal funds is included as well. The 1958 legislation provides perhaps the most interesting policy experiment. The introduction of the variable match rate meant that two states with identical spending beforehand but different incomes saw different price changes. There were 13 states on this segment of the budget constraint in 1958. We can estimate the equation:

$$
\ln (\text { AFDC spending })_{i 59}=\alpha+X_{i 59} \gamma+\eta \ln (\text { AFDC spending })_{i 58}+\kappa N e w \text { Var Match Indic }{ }_{i}+\varepsilon_{i}
$$

to see if those states with a new, more generous, federal match rate changed their behavior more than those whose match rate did not change. The estimate of $\eta$ is .95 (with a robust standard error of .08), while $\kappa$ is .34 (with a robust standard error of .14), suggesting that those states whose match rate jumped (whose marginal price was therefore lower and whose federal income

\footnotetext{
${ }^{7}$ See the Appendix for a more detailed discussion of this kinked budget constraint problem.

${ }^{8}$ The estimate of $\delta_{1}$ is $.13(.06), \phi_{1}$ is $.20(.14), \delta_{2}$ is $.11(.04)$, and $\phi_{2}$ is $-.60(.12)$. When I include a state specific time trend of year fixed effects, the estimate of $\delta_{1}$ is $.22(.05), \phi_{1}$ is $-.11(.05), \delta_{2}$ is $-.26(.04)$, and $\phi_{2}$ is $.36(.05)$. The raw correlation between simulated and actual prices is .77 and between simulated and real federal contributions is .50. Because much of the variation in the instruments comes from the discrete annual changes in the federal statutes, the interpretation of the coefficients in the presence of year dummies is difficult.
} 
was therefore higher) increased their spending relative to those whose price did not change. Since only two states originally on that segment remained at the .5 cap, further decomposition is difficult.

These estimates abstract from the endogenous negative relationship between price and spending in a way that is difficult to do in the absence of changes in legislation governing the federal matching of state spending. We can compare the results in column (3) to Orr's result of .23. Replicating his approach using this data yields very similar estimates, including a mean elasticity of -.26. It is thus the methodology, not the different time period, that is responsible for the difference in results.

Table 3 decomposes the change in state AFDC spending into changes in the number of recipients and changes in the spending per recipient. This decomposition allows us to examine whether or not states respond differently along the intensive and extensive margins. Column (2) shows that the price elasticity of benefit amounts, unlike that of total spending, is negative and significant: a 10 percent increase in the marginal state share of benefits results in a 3 percent decrease in the benefit amount. The income effect of the federal grant is not significant here, and is also not significantly different from the effect of other income. In column (3), however, we see that while federal grants have a significant income effect on recipiency rates, the cross-price elasticity is insignificant: the marginal price of benefits does not seem to affect the number of recipients. These results are consistent with some previous studies and are generated by a more clearly identified source of variation, and suggest the importance of examining own- and crossprice elasticities of both benefits and recipients.

These results are consistent with the previous literature's estimates of price and income elasticities, and highlight the importance of using the instrumental variables approach to abstract 
from the endogeneity of actual price and income. Having established this benchmark, I turn now to the estimation of separate elasticities for state spending on benefits and on recipients that this particular data allows.

\section{Separate Intensive and Extensive Price Elasticities}

As suggested by the model, we would like to include separately the marginal cost of increasing recipients and the marginal cost of increasing benefits on AFDC spending. What are these costs? The cost of adding one recipient is just the benefit paid to that recipient times the fraction of that benefit for which the state is responsible (or the average state share of benefits). The cost of increasing benefits is the fraction of that benefit for which the state is responsible (or the marginal share) times the number of recipients to whom that additional benefit must be paid. Thus, the estimating equation is:

$$
\begin{aligned}
\ln (\text { AFDCSpending })_{i t}= & \alpha_{i}+\beta_{t}+X_{i t} \gamma+\lambda \ln (\text { marginal state share } * R)_{i t}+\phi \ln (\text { average state share } B)_{i t} \\
& +\theta \ln (\text { federal AFDC contribution })_{i t i t}+\varepsilon_{i t}
\end{aligned}
$$

$\lambda$ estimates the elasticity of spending with respect to the marginal cost of additional benefits, while $\phi$ estimates the elasticity of spending with respect to the marginal cost of additional recipients. For the same reasons as above we would want to instrument for the two marginal costs and the federal income using simulated values. ${ }^{0}$ Again, the instruments are jointly and individually significant in all three first stage regressions. Table 4 shows these results, along

\footnotetext{
${ }^{9}$ Greater precision can be obtained by including the components of the simulated values (the match rate and kink points for each segment in each state-year) as well. These results are reported, but are quite similar in magnitude to results using just the simulated values.
} 
with a decomposition of total spending per capita into benefits per recipients and recipients per capita.

Column (1) shows the effect of the two marginal costs on total spending. The elasticity of total spending with respect to the cost of adding benefits is -.25 (with a robust standard error of .10), while the elasticity with respect to the cost of adding recipients is an insignificant -.02 . As above, a decomposition of total spending into its component parts (shown in columns (2) and (3) yields much more information about the elasticities. Each of the own-price elasticities is negative and significant: the elasticity of benefits with respect to the price of benefits is -.38 , while the elasticity of recipients with respect to the price of recipients is -.34 . The cross-price elasticities are both positive, although only one is significant. When the price of recipients goes up by 10 percent, spending on benefits goes up by 3.2 percent (with a robust standard error of .10 ), while when the price of benefits goes up by 10 percent, the number of recipients goes up by an insignificant 1.3 percent. The magnitude of the own-price elasticities is consistent with previous studies discussed above, but there is little previous evidence on cross-price elasticities with which to compare these results. It is worth noting that in each case there is still a significant positive federal AFDC income effect, greater than would be predicted by traditional economic models, consistent with the flypaper effect literature. Again, the presence of this income control allows us to interpret the prices coefficients as (Slutsky) compensated elasticities.

Theoretically we could also use these instruments to estimate the causal effect of a change in the AFDC spending of neighboring states on a state's own AFDC spending, but because the initial spending of neighboring states is correlated, the timing of the shocks is correlated across states, and composite "neighbors" are only weakly correlated with the composite instruments, precise estimation of this spillover is not possible in this framework. 
The primary insight to be gained from this analysis is that when separate incentives existed for spending along the intensive and extensive margins, states responded in the way that theory would predict. The more expensive it was to spend on increased benefits, states substituted away from benefits and towards additional recipients, and similarly when it was more expensive to increase eligibility and add recipients, the less likely states were to do so. The estimated price elasticities are statistically and economically significant, and imply that there are two different margins along which the subsidies generated by federal grants can affect welfare spending.

\section{The Effect on Program Features}

As the history of state AFDC eligibility patterns suggests, states had both the freedom and the desire to manipulate the eligibility along different population characteristics, such as race. Unfortunately, more detailed information on recipient characteristics at the state level is not available, so it is not possible to see how changes in price affected the characteristics of the recipient pool. It is possible, however, to look more closely at some of the eligibility restrictions imposed by the state. State programs vary along several dimensions, such as the presence of residency requirements and work requirements, and whether or not local spending is subject to a state-wide cap. Many of these provision are summarized in the publication Characteristics of State Programs.

I use a linear probability model to see whether or not prices affect the likelihood of the presence of two restrictive policies: the presence of "work" requirements, stipulating that the head of the household may not refuse available work (often with the provision that suitable child 
care also be available) and the imposition of "suitable home" requirements, discussed above. Both of these provisions were designed to affect eligibility and thus the number of recipients, not the benefit amount per recipient. We would thus expect the likelihood of the imposition of such benefits to go up with the price of recipients and to go down with the price of benefits, consistent with the cross-price substitution effect seen in Table 4.

The linear probability results shown in Table 5 are consistent with this behavior, although many of the coefficients are insignificant. The results suggest that as the price of adding recipients goes up, states are more likely to impose work or home requirements, but as the price of adding benefits goes up states are less likely to impose such restrictions.

\section{Conclusions}

This paper explores state reactions to the form and size of federal welfare grants under a regime where the marginal price of expanding eligibility and the marginal price of increasing benefits per recipient differ, which allows separate estimation of elasticities along the extensive and intensive margins of welfare generosity in a way that cannot be done using recent data. I am able to abstract from the confounding effects of state income and spending choices by using legislative changes in the AFDC program to estimate the causal effects of different federal match rates along these dimensions on total state spending, benefits per recipient, and recipiency rates. I find that the benefit amount responds significantly to the marginal price of benefits, with an

\footnotetext{
${ }^{10}$ I have only four volumes of this annual publication, yielding 192 observations. Values in between these years can be interpolated.

${ }^{11} 9$ states had suitable home requirements at some point during this period: AR, FL, GA, LA, MI, MS, TN, TX, and VA. 20 states had work requirements: AL, AR, AZ, CA, DE, FL, GA, IL, MI, MN, MO, MS, NE, NH, NM, RI, $\mathrm{SC}, \mathrm{TN}, \mathrm{TX}$, and WV.
} 
elasticity of -.38 , and that the number of recipients responds significantly to the marginal price of additional recipients, with an elasticity of -.34 . Cross-price elasticities are positive, so that an analysis that groups the two margins together masks informative behavioral responses to the marginal subsidies. Results also suggest that during this period states reacted to the marginal price of recipients in part by controlling eligibility through the imposition of potentially discriminatory recipiency requirements.

These estimates give us some insight into likely state responses to federal welfare reform. There are some difficulties inherent in using data from a quite different era: the political climate, institutions, regulations and legislation, and menu of programs available 30 to 40 years ago have certainly changed (for example, with the advent of Medicaid). Looking at this period does, however, offer substantial advantages: while states have always been able to adjust their behavior along different margins, in this period we can distinguish separate prices for two of these margins, and federal rule changes allow the creation of simulated prices that are not affected by economic and political conditions and the like.

Applying the elasticities from that period to the current welfare reform yields some illustrative benchmarks. States faced a marginal price (for both benefits and recipients) of around 40 cents on the dollar on average in 1995. TANF increased the price of either kind of spending to 1 , keeping the size of the federal grant the same. This represented an increase in both prices of 120 percent. Applying the elasticities of -.25 and -.02 from the first column of Table 4 suggests that this would decrease total spending by about 37 percent. The estimates from columns (2) and (3) tell us more than that, however: the reduction would come almost entirely from decreasing recipients, not from decreasing benefits per recipient. The decrease in benefits implied by column (2) is an insignificant 7 percent, while the decrease in recipients implied by 
column (3) is 25 percent. In fact, caseloads fell by 40 percent from 1994 to 1998, without a corresponding drop in benefits per recipient (Wallace and Blank, 1999). While there is much debate about the degree to which this fall can be attributed to the implementation of TANF, rather than underlying economic conditions, these results strongly suggest the importance of state responses to federal incentives.

This does not, however, answer the question of whether or not having equal (or zero) subsidies along both dimensions is optimal. For example, if states expand eligibility in order to enable residents to enroll in federal programs whose eligibility is tied to welfare receipt, the federal government might want to subsidize additional recipients at a lower rate than additional benefits per recipient. If states reduce eligibility to decrease cross-state immigration that imposes an externality, more generous subsidy of recipients might be efficient. Knowing that states respond to these subsidies significantly and differentially allows the design of optimal welfare financing that incorporates such externalities. 


\section{REFERENCES}

Bateman, Peter, Administration of AFDC in Massachusetts: A Description of Three Local Offices, Abt Associates, Cambridge, 1980.

Bell, Winifred, Aid to Dependent Children, Columbia University Press, New York, 1965.

Clines, Francis X., Clinton Signs Bill to Cut Welfare and Change State Role, New York Times, August 23, 1996.

Congressional Research Service, Analysis of Federal-State Cost-Sharing in the Aid to Families With Dependent Children Program, Report No. 82-62 EPW, 1982.

Chernick, Howard, Federal Grants and Social Welfare Spending: Do State Responses Matter?, National Tax Journal, Vol. LII, No. 1.

Chernick, Howard, Fiscal Effects of Block Grants for the Needy: An Interpretation of the Evidence, International Tax and Public Finance, Vol. 5 no. 2, 1998.

Gordon, Linda, Pitied But Not Entitled: Single Mothers and the history of Welfare 1890-1935, The Free Press, New York, 1994.

Hines, James R. Jr., and Richard Thaler, Anomalies: The Flypaper Effect, Journal of Economic Perspectives 9 (4), Fall 1995, pp 217-26.

Howard, Donald S., The WPA and Federal Relief Policy, Russell Sage Foudnation, New York, 1943.

Moffitt, Robert A., The Effects of Grants-In-Aid on State and Local Expenditures: The Case of AFDC, Journal of Public Economics, 1984, pp 279-305.

Moffitt, Robert A., The Econometrics of Piecewise-Linear Budget Constraints, Journal of Business \& Economic Statistics, July 1986, Vol. 4 No. 3.

Moffitt, Robert A., Has State Redistribution Policy Grown More Conservative?, National Tax Journal, Vol. 43, June 1990.

Orr, Larry L., Income Transfers as Public Good: An Application to AFDC, American Economic Review, June 1976, pp 359-371.

Ribar, David C. and Mark O. Wilhelm, The Demand for Welfare Generosity, The Review of Economics and Statistics, February 1999, 81(1): 96-108.

U.S. Department of Health, Education and Welfare, Characteristics of State Public Assistance Plans Under the Social Security Act, Public Assistance Report No. 40, Washington DC, various years.

U.S. Department of Health, Education, and Welfare, Annual Report, U.S. G.P.O., various years.

U.S. Federal Security Agency, Annual Report, U.S. G.P.O., various years.

Wallace, Geoffrey and Rebecca Blank, What Goes Up Must Come Down? in Economic Conditions and Welfare Reform (Sheldon Danziger, editor), W.E. Upjohn Institute, 1999. 


\section{APPENDIX: THE AFDC BUDGET CONSTRAINT}

The nature of the federal AFDC matching rate schedule during this sample period is such that states face a kinked budget constraint: as their benefit amount increases, the marginal price of that spending ( 1 - the federal match) increases discretely, as shown in Figures 1 and 2. The budget constraint in Figure 2 represents a fixed number of recipients; a change in the choice of the number of recipients shifts the schedule.

The 1948, 1950, 1952, and 1956 Amendments changed the kink points and match rates for the segments. The 1958 Amendments made the match rate in the second segment depend on state income. In every case, the budget set remained convex for each state. In no case were the kink points changed without simultaneous price changes, nor were prices changed without simultaneous changes in the kink points.

I instrument for the actual marginal and average prices and federal income faced by states with simulated prices and income, generated by making an assumption about state spending on AFDC (such as that the recipient to population ratio and real benefits are held constant at 1948 levels) and projecting what marginal price and federal income each state would face given current legislation. A problem inherent in this estimation technique is that in response to legislative changes (or any other changes), states may change their spending such that they are on a different segment of the budget constraint. This is in fact the only circumstance in which the simulated price is different from the actual price. This would be troubling if the budget constraint were not convex. In the case of non-convex constraints, we might see the perverse result that a decrease in the federal subsidy for AFDC caused an increase in spending on AFDC, if the location of the global maximum switched segments. 12

\footnotetext{
${ }^{12}$ See Moffitt (1984) for a discussion of the theoretical issues and econometric techniques involved with this kind of estimation. He estimates a structural demand model to determine states' segment choice.
} 
One way to investigate the importance of these kinks in state spending on AFDC is to see how many states choose to locate at the kink point. Figure A is a histogram of average state monthly spending per recipient by year.

Figure A: State Spending per Recipient by Year

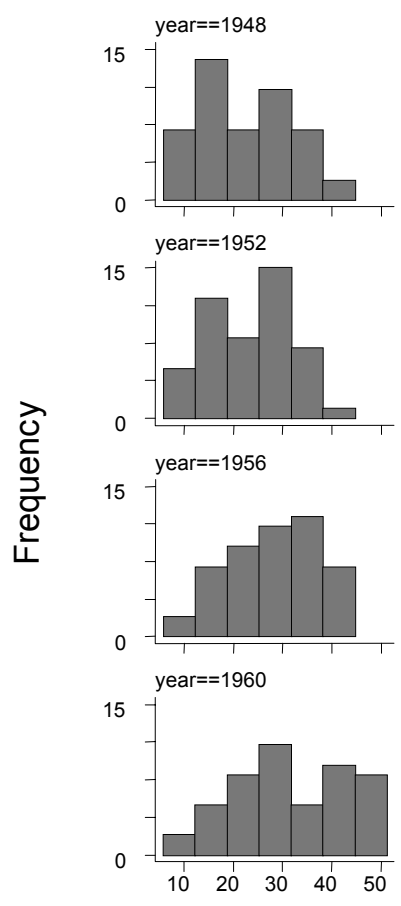

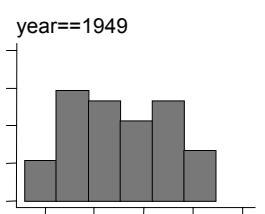

year $==1953$

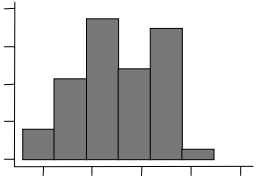

year $==1957$
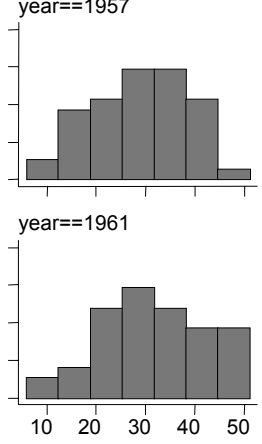
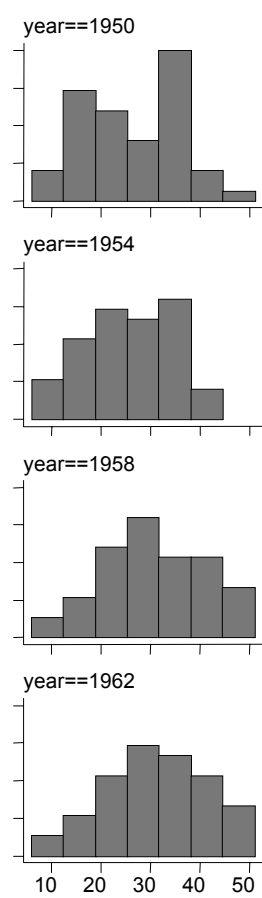
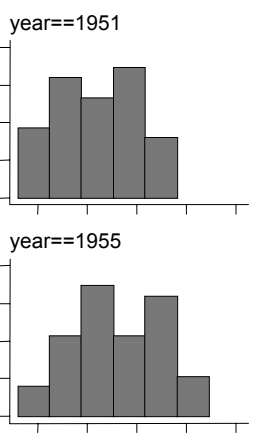

year $==1959$

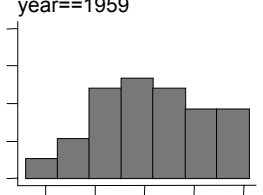

year $==1963$

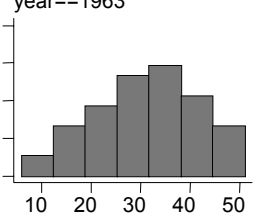

Average Monthly Payment per Recipient

In each year there are two kink points, corresponding to $\mathrm{p}_{1}$ and $\mathrm{p}_{2}$. These kinks are given in Figure 1. For example, in 1948, states received $2 / 3$ of the first 9 dollars per recipient per month and $1 / 2$ of remainder up to 24 dollars. An added complication is that until 1959 the second kink point was higher for the first child than it was for subsequent children. (This point was 15 dollars in 1948, 18 from 1949 to 1952, 21 from 1953 to 1956, and 23 in 1957 and 1958.) This means that the second kink point will be blurred on the histograms, based on the different family sizes across states (even assuming that family 
size is exogenous to state spending on AFDC). Despite these complications, there does not seem to be much bunching of states at the kink points.

A more rigorous measure of state location is to evaluate how many states would switch segments for a given change in prices. Using the estimated match elasticity of state spending per recipient of -..3, a one standard deviation change in the match rate would yield about a 3 dollar change in benefits per recipient. 37 percent of state-years are located within 3 dollars of a kink point, but they are located quite symmetrically above and below.

\footnotetext{
${ }^{13}$ There are 139 observations within $\$ 3$ below and 147 within $\$ 3$ above, with each year represented above and below, 31 states represented below, and 25 above. There are 105 observations within $\$ 2$ below and 103 within $\$ 2$ above, with each year represented above and below, 30 states represented below, and 22 above.
} 


\section{Figure 1: Federal Match Rates versus Monthly Spending per Recipient}

\section{Years Corresponding to Law Changes Shown}
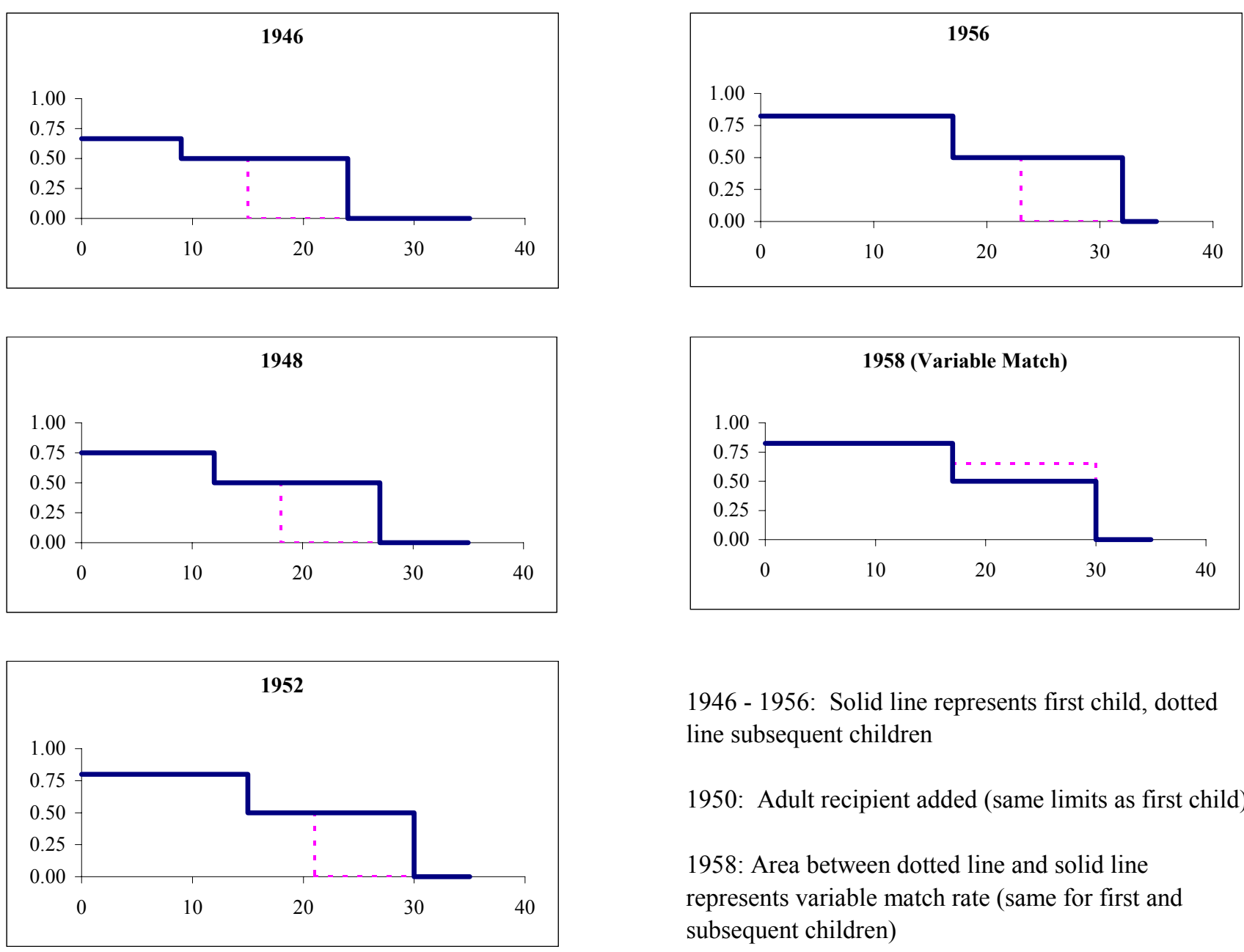

1946 - 1956: Solid line represents first child, dotted line subsequent children

1950: Adult recipient added (same limits as first child)

1958: Area between dotted line and solid line represents variable match rate (same for first and subsequent children) 


\section{Figure 2: Sample Budget Constraints}

\section{Spending on Other Goods vs. AFDC}

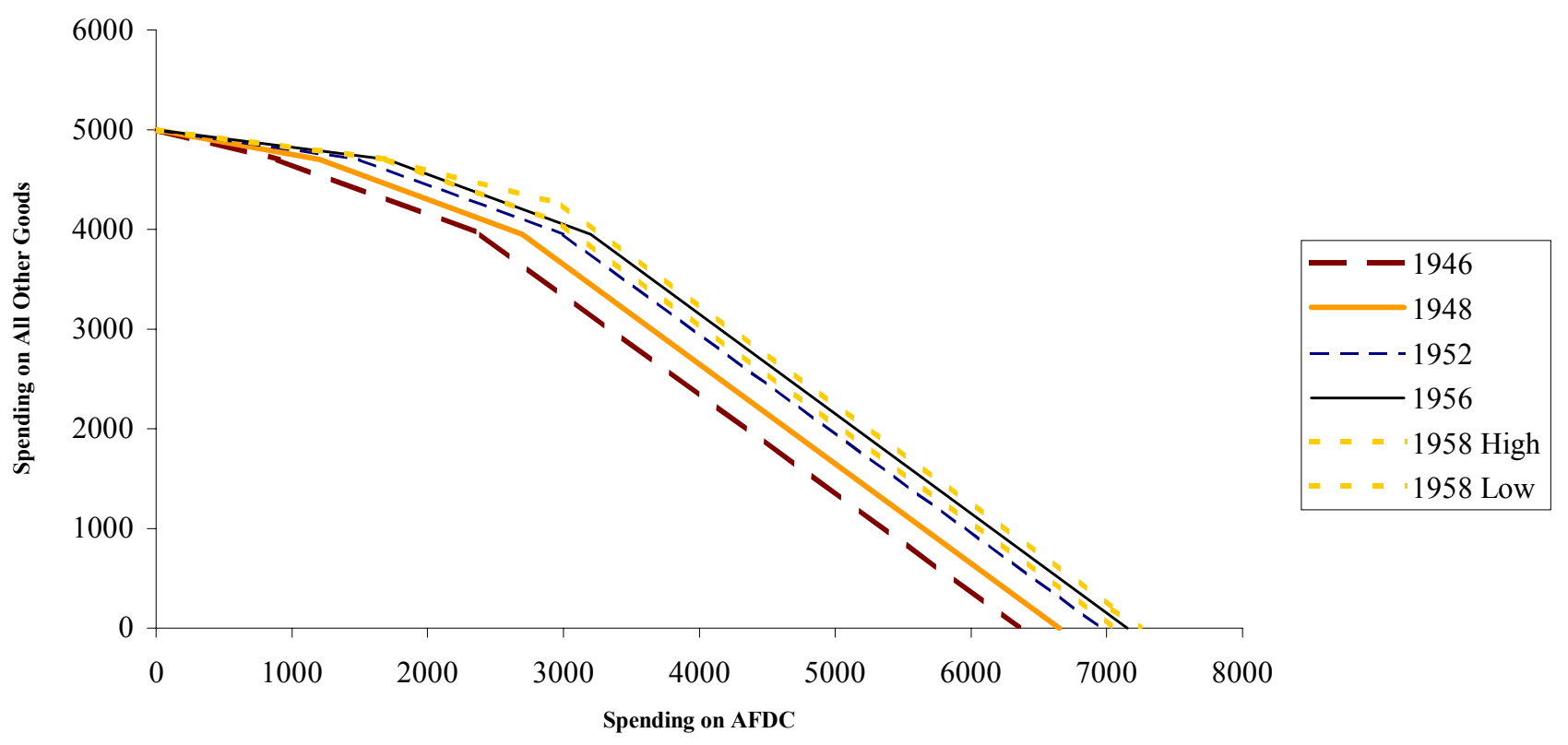




\section{Table 1: Summary Statistics}

\begin{tabular}{lll}
\hline \hline & Mean & Std Dev
\end{tabular}

Per Capita State General Expenditures:

Total

Public Welfare

Recipients per Capita

Annual Benefit per Recipient

AFDC

Actual Federal AFDC Contribution

Simulated Federal AFDC Contribution
791.9

111.3

0.014

2078

27.7

16.8

13.7

0.39

Simulated Average Share

Actual Marginal Share

Simulated Marginal Share
0.16

268.6

55.4

0.008

733

15.0

9.9

7.6

0.10

0.30

0.34
0.24

0.74

0.62

11,110

4.0

14.4

0.32

0.08

\section{Other Variables:}

Per Capita Personal Income

Covered Unemployment

AFDC Recipients / 1,000 Population

Work Requirement Indicator

Suitable Home Requirement Indicator
2,605

1.9

8.2

0.47

0.28

Notes and Sources: $\quad$ Sample includes observations for the 48 continental states from 1948 through 1963 Data is from the Statistical Abstract of the United States unless noted.

All expenditures are in real 2000 dollars per capita.

"Covered" refers to unemployment covered by unemployment insurance and is taken from the UI Handbook.

"Simulated" state share and federal AFDC income is created by applying legislative changes in the federal share to initial levels of state spending. 
Table 2: Income and Price Elasticities of State AFDC Spending

Dependent Variable: Ln (Real Per Capita State Expenditure on AFDC)

(Robust Standard Errors)

\begin{tabular}{|c|c|c|c|c|}
\hline & \multicolumn{2}{|c|}{ OLS } & \multicolumn{2}{|r|}{ IV } \\
\hline & \multicolumn{2}{|c|}{$\begin{array}{l}\text { Actual State Share and Federal } \\
\text { AFDC Funds }\end{array}$} & \multicolumn{2}{|c|}{$\begin{array}{c}\text { Simulated State Share and Federal } \\
\text { AFDC Funds }\end{array}$} \\
\hline & (1) & (2) & (3) & (4) \\
\hline Ln (Marginal State Share) & $\begin{array}{r}0.42 \\
(0.09)\end{array}$ & $\begin{array}{r}0.09 \\
(0.02)\end{array}$ & $\begin{array}{r}-1.16 \\
(0.52)\end{array}$ & $\begin{array}{r}-0.18 \\
(0.12)\end{array}$ \\
\hline Ln (Federal AFDC Income) & & $\begin{array}{r}0.58 \\
(0.19)\end{array}$ & & $\begin{array}{r}1.24 \\
(0.18)\end{array}$ \\
\hline Ln (Per Capita Personal Income) & $\begin{array}{r}-0.25 \\
(0.25)\end{array}$ & $\begin{array}{r}0.30 \\
(0.12)\end{array}$ & $\begin{array}{r}-0.81 \\
(0.44)\end{array}$ & $\begin{array}{r}0.52 \\
(0.15)\end{array}$ \\
\hline Ln (Covered Unemployment Rate) & $\begin{array}{r}-0.03 \\
(0.05)\end{array}$ & $\begin{array}{r}0.05 \\
(0.03)\end{array}$ & $\begin{array}{r}0.10 \\
(0.08)\end{array}$ & $\begin{array}{r}0.11 \\
(0.03)\end{array}$ \\
\hline Year Fixed Effects & & & & \\
\hline State Fixed Effects & $\begin{array}{r}1.81 \\
(1.28)\end{array}$ & $\begin{array}{r}2.80 \\
(0.70)\end{array}$ & $\begin{array}{r}-3.93 \\
(2.89)\end{array}$ & $\begin{array}{r}2.67 \\
(0.84)\end{array}$ \\
\hline R-squared & 0.78 & 0.93 & 0.47 & 0.82 \\
\hline
\end{tabular}

Notes: Sample includes observations for the 48 continental states from 1948 through 1963 (N=768).

Data is from the Statistical Abstract of the United States. All expenditures are in real 2000 dollars per capita. "Covered" refers to unemployment covered by unemployment insurance and is taken from the UI Handbook.

"Simulated" State Share and Federal AFDC Income are created by applying legislative changes in the federal share to initial (1948) levels of state spending. 
Table 3: Decomposing the Price and Income Effects

IV Specification:

Actual state share and federal AFDC income instrumented with simulated values

Dependent Variable:

Ln (Total AFDC
spending
per capita)

Ln (AFDC
benefits
per recipient)

Ln (AFDC

per capita)

(2)

recipients

(1)

(3)

Ln (Marginal State Share)

Ln (Federal AFDC Income)

Ln (Per Capita Personal Income)

Ln (Covered Unemployment Rate)

Year Fixed Effects

State Fixed Effects

R-squared
$-0.18$

(0.12)

1.24

(0.18)

0.52

$(0.15)$

0.11

(0.03)

yes

yes

0.82
$-0.31$

(0.12)

0.18

(0.15)

0.36

(0.16)

0.09

(0.02)

(0.02)

yes

yes

yes

0.90

0.87

Notes and Sources: $\quad$ Sample includes observations for the 48 continental states from 1948 through 1963 (N=768).

Data is from the Statistical Abstract of the United States. All expenditures are in real 2000 dollars per capita.

"Simulated" State Share and Federal AFDC Income are created by applying legislative changes in

the federal share to initial (1948) levels of state spending.

"Covered" refers to unemployment covered by unemployment insurance and is taken from the UI Handbook. 
Table 4: Intensive and Extensive Price Elasticities

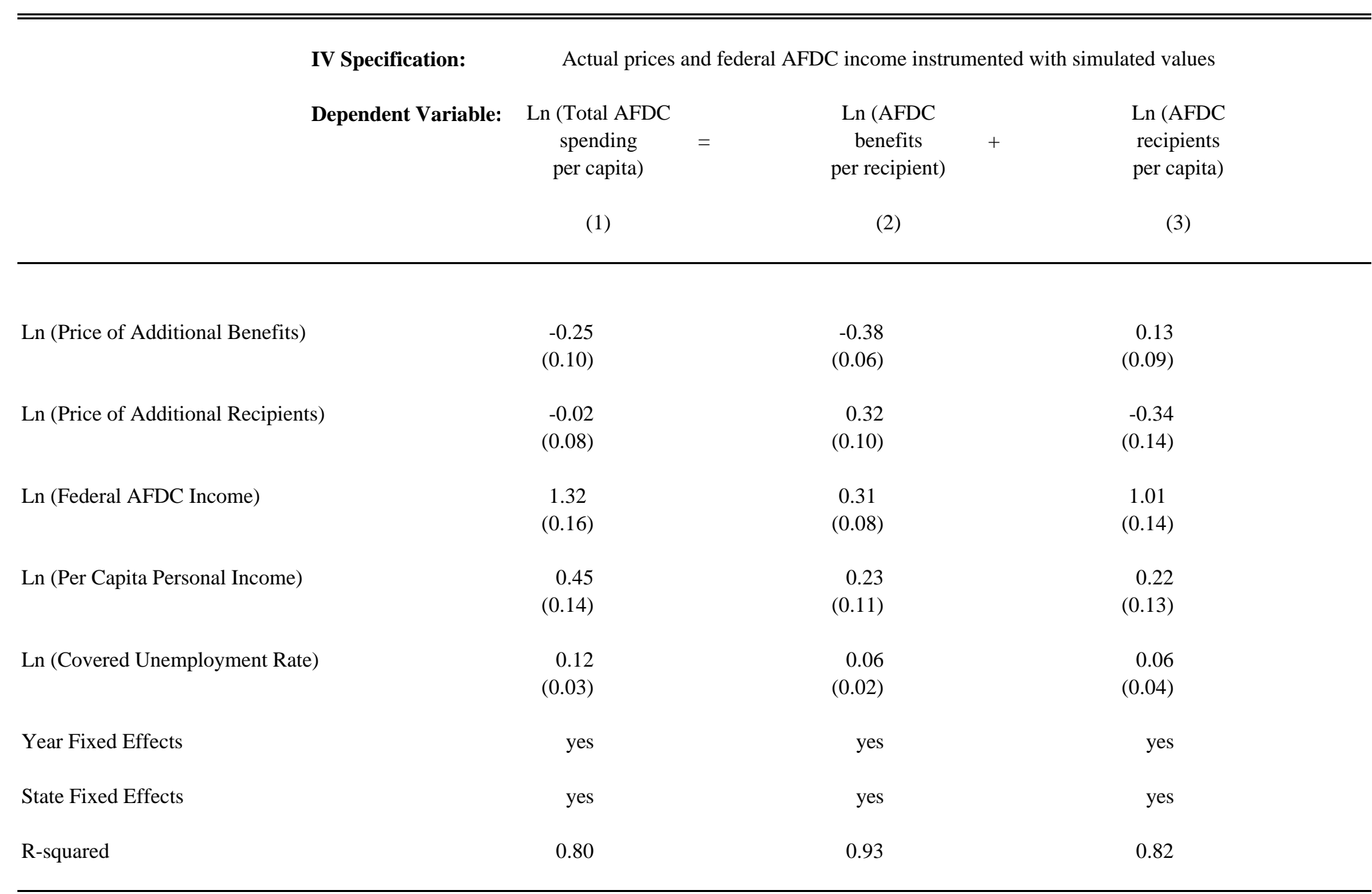

Notes and Sources: Price of additional benefits is the marginal state share times the number of recipients. Price of additional recipients is the average state share times the benefit amount.

Instruments also include kink points and match rates for each segment of the schedule.

Sample includes observations for the 48 continental states from 1948 through 1963 (N=768).

Data is from the Statistical Abstract of the United States. All expenditures are in real 2000 dollars per capita.

"Simulated" State Share and Federal AFDC Income are created by applying legislative changes in the federal share to initial (1948) levels of state spending.

"Covered" refers to unemployment covered by unemployment insurance and is taken from the UI Handbook. 


\section{Table 5: Effects on Recipiency Requirements}

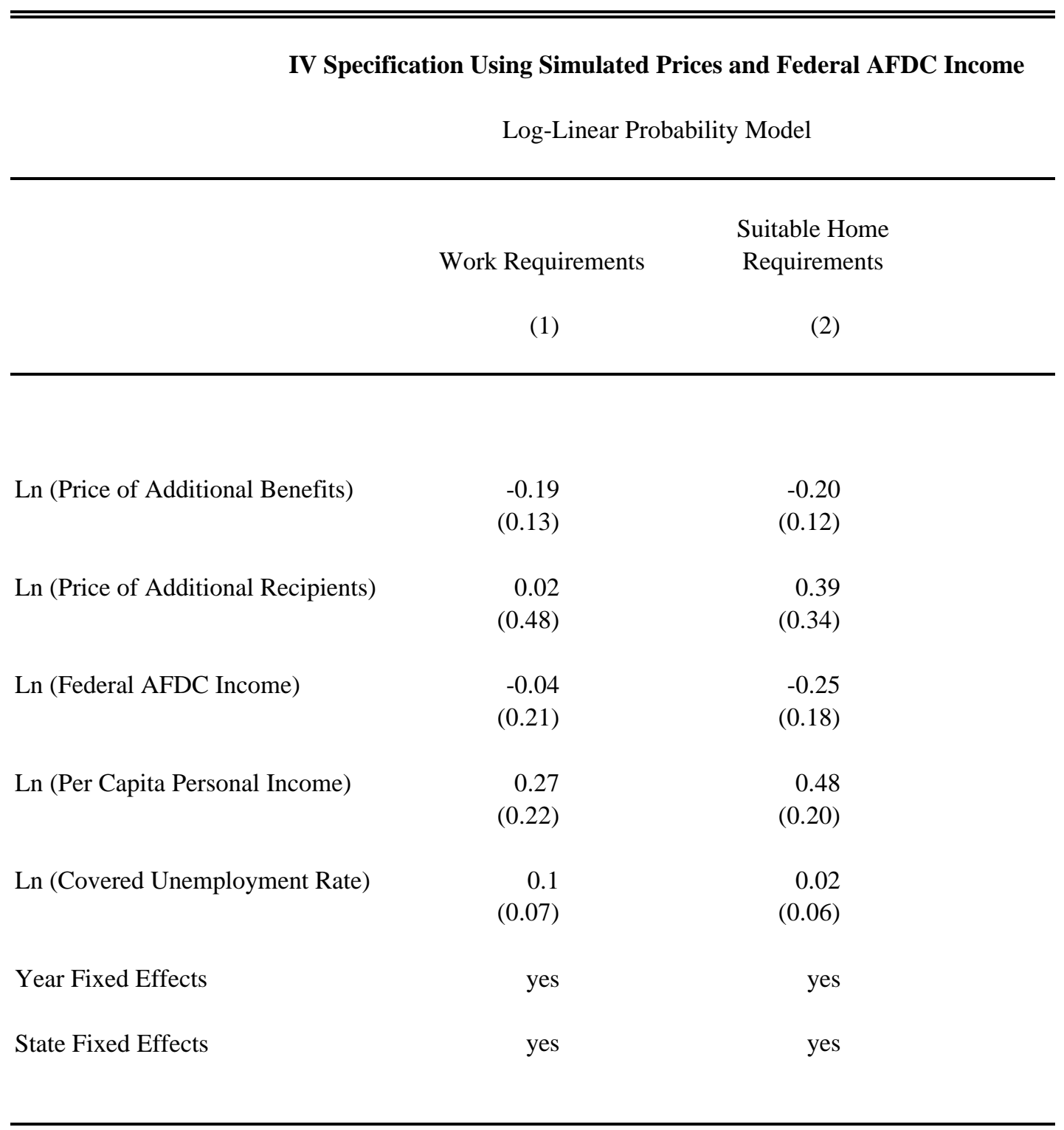

Notes: Program data on work requirements interpolated from 4 available years (1952, 1955, 1957, and 1959), reported in "Characteristics of State Plans". Suitable home requirements from Bell.

"Simulated" State Share and Federal AFDC Income are created by applying legislative changes in the federal share to initial (1948) levels of state spending. 